\title{
A Report of the Mayo Clinic Experience on the Levothyroxine Absorption Test
}

\section{Bernadette Biondi}

\author{
Department of Clinical Medicine and Surgery, University of Naples Federico II, Italy
}

Review of: Gonzales KM, Stan MN, Morris JC III, Bernet V, Castro MR 2019 The levothyroxine absorption test: a four-year experience (2015-2018) at the Mayo Clinic. Thyroid. Epub 4 Dec 2019. PMID: 31680654.

\section{SUMMARY}

\section{Background}

The optimal starting replacement dose of levothyroxine $\left(\mathrm{L}-\mathrm{T}_{4}\right)$ related to body weight $(\mathrm{BW})$ is about 1.6 to $1.8 \mu \mathrm{g} / \mathrm{kg} /$ day in hypothyroid adults (1). This dosage can vary according to the etiology and severity of the hypothyroidism, the patient's age, and any associated comorbidities (1). Consequently, the dose of $\mathrm{L}-\mathrm{T}_{4}$ should be adjusted on the basis of the evaluation of serum thyrotropin (TSH) levels, which represent the best marker of the adequacy of ${\mathrm{L}-\mathrm{T}_{4}}_{4}$ prescription in primary hypothyroidism; the TSH cut-off level should be targeted according to the patient's age and other factors, as mentioned above (1,2).

Refractory hypothyroidism is defined by a persistent TSH increase during the administration of a supraphysiological weight-based dose of $\mathrm{L}-\mathrm{T}_{4}(2)$, which is usually a levothyroxine requirement of $\geq 1.9 \mu \mathrm{g} / \mathrm{kg} /$ day in patients with primary hypothyroidism. In this condition, it is mandatory to investigate the patient's compliance, nutrients, food and drug interferences, and possible gastrointestinal disorders. The oral $\mathrm{L}-\mathrm{T}_{4}$ absorption test has been supported by some clinicians for the differentiation of malabsorption, which is due to gastrointestinal disorders, from pseudomalabsorption, a condition due instead to intentional nonadherence to treatment (3-7).
In this study (8), authors at the Mayo Clinic report their experience with patients diagnosed with refractory primary hypothyroidism. The study provides important information on the dosage of $\mathrm{L}-\mathrm{T}_{4}$, serum total thyroxine $\left(\mathrm{TT}_{4}\right)$ assessments, and percent absorption for the interpretation of the levothyroxine absorption test, in order to distinguish between malabsorption and pseudomalabsorption.

\section{Methods}

This retrospective study was performed by the Mayo Clinic to assess their 4-year experience with the $\mathrm{L}-\mathrm{T}_{4}$ absorption test. The primary aim of this study was to assess the usefulness of the levothyroxine absorption test in distinguishing $\mathrm{L}-\mathrm{T}_{4}$ malabsorption from pseudomalabsorption in patients with hypothyroidism. Secondary aims were to determine whether the results of this test impact clinical management decisions and outcomes during the follow-up.

Sixteen patients age $\geq 18$ years with primary refractory hypothyroidism who had undergone the $\mathrm{L}-\mathrm{T}_{4}$ absorption test were identified between January 2015 and January 2019 (8). Only 13 of the patients had available $\mathrm{TT}_{4}$ data; percent absorption was calculated for these patients. A 6-hour $\mathrm{L}^{-\mathrm{T}_{4}}$ absorption test was performed on the basis of a weight- and age-based dose of L-T $4600 \mu \mathrm{g}, 1000 \mu \mathrm{g}$, and 1500 $\mu \mathrm{g}$ ), followed by serial measurements of $\mathrm{TT}_{4}$ and 
TSH. Percent absorption was calculated using the following formula:
$\%$ absorbed $=\left\{\left[\right.\right.$ increment $\left.\mathrm{TT}_{4}(\mu \mathrm{g} / \mathrm{dl}) \times 10(\mathrm{dl} / \mathrm{L})\right]$ / total administered $\left.\left.\mathrm{L}-\mathrm{T}_{4}(\mu \mathrm{g})\right]\right\}$ $\times \mathrm{Vd}(\mathrm{L}) \times 100$,

where $\mathrm{Vd}$ denotes volume of distribution. $\mathrm{TT}_{4}$ was measured at baseline and after 1 hour, 2 hours, 3 hours, 4 hours, and 6 hours. Serum TSH was assessed at baseline and after 6 hours. Normal absorption was considered to be $\geq 60 \%$.

\section{Results}

In the study cohort, $94 \%$ of patients were females (age range, 19 to 60 years). The average weight was $91.1 \mathrm{~kg}$ (median, $90.2 \mathrm{~kg}$ ), and the body-mass index (BMI; the weight in kilograms divided by the square of the height in meters) was 32.5 (median, 31.4). The etiology of hypothyroidism was postsurgical in $37.5 \%$ of patients and autoimmune in $43.8 \%$. The cause of hypothyroidism was unknown in $18.8 \%$ of the cases.

Patients were investigated to assess relevant comorbidities and drugs interferences, and some underwent additional procedural testing. A diagnostic workup to detect gastrointestinal disorders was performed in $87.5 \%$ of the patients, which was based on clinical features and tests that included serum tissue transglutaminase IgA antibody concentrations, endoscopy with duodenal biopsies, and stool studies.

The percent absorption during the $\mathrm{L}-\mathrm{T}_{4}$ absorption test was calculated in only 13 of the 16 patients owing to the lack of serum $\mathrm{TT}_{4}$ data in 3 patients. Of these 13 patients, 12 had normal absorption by hour 4 of the test (\% absorption, 60-158), in conjunction with rising serum $\mathrm{TT}_{4}$ trends, and 1 demonstrated severe hypothyroidism due to complete malabsorption (\% absorption, 0), whose condition improved after intravenous $\mathrm{L}^{-\mathrm{T}_{4}}$ administration. No adverse events were reported during any of the tests.

\section{Conclusions}

In adults with refractory hypothyroidism, the L-T 4 absorption test can provide helpful information to distinguish malabsorption from pseudomalabsorption. Both the calculated percentage absorption and serum $\mathrm{TT}_{4}$ trends over at least 4 hours could be sufficient to assess $\mathrm{L}-\mathrm{T}_{4}$ absorption.

\section{COMMENTARY}

The $\mathrm{L}-\mathrm{T}_{4}$ absorption test has been proposed as a diagnostic tool to differentiate between malabsorption and pseudomalabsorption. However, there are heterogeneous protocols and no well-established standards for this test at present (3-7). This study reports on the Mayo Clinic's 4-year experience with the L-T 4 absorption test and presents a useful strategy to perform the test (8). By using a single large dose of $\mathrm{L}-\mathrm{T}_{4}$ with weight-based calculations and lower doses of $\mathrm{L}-\mathrm{T}_{4}$ in elderly patients, the protocol manages to limit potential adverse effects. The proposed dose of $\mathrm{L}-\mathrm{T}_{4}$ administered was probably higher than the dose needed to demonstrate adequate absorption on the basis of serum $\mathrm{TT}_{4}$ changes. It is plausible that this protocol could be further individualized with a dose precisely calculated on a patient's weight-based total weekly L-T 4 dose.

Pseudomalabsorption is a difficult diagnosis and is frequently associated with psychiatric disorders. Common measures for assessing compliance (including pill counting, counseling methods, interviews, and greater vigilance for the patient's L-T 4 ingestion) only infrequently improve this condition (1). Noncompliant patients may be recommended a trial regimen that involves taking their entire $\mathrm{L}-\mathrm{T}_{4}$ 
dose once a week or half the dose twice a week (2). However, this approach should be avoided in patients with underlying heart disease (1).

Conversely, malabsorption should be promptly treated with increasing doses of $\mathrm{L}-\mathrm{T}_{4}$ to normalize the serum TSH concentration (1,2,9). Frequent fluctuations in serum TSH can be observed in patients with transient and persistent conditions of malabsorption. New hormonal liquid formulations and soft-gel capsules can allow for a faster absorption of thyroxine than tablet formulations because of the lack of a dissolution phase (9). Some case series and two meta-analyses have demonstrated their beneficial effects in improving $\mathrm{L}-\mathrm{T}_{4}$ compliance and absorption in patients with gastrointestinal disorders or in those ingesting drugs that interfere with L-T 4 absorption (9). Intra- venous administration of $\mathrm{L}-\mathrm{T}_{4}$ should be reserved for patients with severe and persistent hypothyroidism in which the cause of malabsorption cannot be identified. However, in some countries, intravenous $L-T_{4}$ is not routinely available or is particularly expensive. A case series on three patients who had undergone thyroidectomy with refractory hypothyroidism identified the possibility of treating patients using a liquid preparation with a sublingual route of administration (10).

Further studies are necessary to clarify the pathophysiological mechanisms of thyroxine absorption at the intestinal level, with regard to intestinal transport pathways, to improve the use of $\mathrm{L}-\mathrm{T}_{4}$ absorption test. Additionally, pharmacokinetic studies could help to shed light on the potential use of the sublingual route in patients with severely resistant hypothyroidism.

\section{Refierences}

1. Biondi B, Wartofsky L 2014 Treatment with thyroid hormone. Endocrine Rev 35:433-512.

2. Jonklaas J, Bianco AC, Bauer AJ et al. 2014 Guidelines for the treatment of hypothyroidism: prepared by the American Thyroid Association Task Force on Thyroid Hormone Replacement. Thyroid 24:1670-1751.

3. Lips DJ, van Reisen MT, Voigt V, Venekamp W 2004 Diagnosis and treatment of levothyroxine pseudomalabsorption. Neth J Med 62:114-118.

4. Morris JC 2009 How do you approach the problem of TSH elevation in a patient on high-dose thyroid hormone replacement? Clin Endocrinol (Oxf) 70:671-673.

5. Ain KB, Refetoff S, Fein HG, Weintraub BD 1991 Pseudomalabsorption of levothyroxine. JAMA 266:2118-2120.

6. Srinivas V, Oyibo SO 2010 Levothyroxine pseudomalabsorption and thyroxine absorption

testing with use of high-dose levothyroxine: case report and discussion. Endocr Pract 16:1012-1015.

7. Walker JN, Shillo P, Ibbotson V, et al. 2013 A thyroxine absorption test followed by weekly thyroxine administration: a method to assess nonadherence to treatment. Eur J Endocrinol 168:913917.

8. Gonzales KM, Stan MN, Morris JC III, Bernet V, Castro MR 2019 The levothyroxine absorption test: a four-year experience (2015-2018) at the Mayo Clinic. Thyroid. Epub 4 Dec 2019.

9. Virili A, Antonelli MG, Santaguida S, Benvenga S, Centanni M 2019 Gastrointestinal malabsorption of thyroxine. Endocr Rev 40:118-136.

10. Peirce C, Ippolito S, Lanas A, Pesce M, Pontieri G, Arpaia D, Sarnelli G, Biondi B 2018 Treatment of refractory and severe hypothyroidism with sublingual levothyroxine in liquid formulation. Endocrine 60:193-196. 